\title{
Rb-Sr systematics of the ungrouped achondrites
}

\author{
E.A. KRESTIANINOV ${ }^{1 *}$ AND Y.AMELIN ${ }^{1}$
}

${ }^{1}$ Research School of Earth Sciences, The Australian National University (*evgenii.krestianinov@anu.edu.au)

Initial $\mathrm{Sr}$ chronometry was proposed by [1] and based on different condensation temperature of $\mathrm{Rb}(\approx 800 \mathrm{~K})$ and $\mathrm{Sr}$ $(\approx 1465 \mathrm{~K})$ [2]. It allows estimating the time of separation of the low- $\mathrm{Rb} / \mathrm{Sr}$ achondrite precursors from high- $\mathrm{Rb} / \mathrm{Sr}$ solar nebula [3] by comparing initial ${ }^{87} \mathrm{Sr} /{ }^{86} \mathrm{Sr}$ of CAIs [4] and achondrites.

We analysed $\mathrm{Rb}-\mathrm{Sr}$ system of eight achondrites: Ibitira, Asuka 881394, NWA 11119, eucrite NWA 8661, NWA 6704, NWA 4587, NWA 7325, and ureilite ALM-A. Two plagioclase fractions from each meteorite (for NWA 4587 whole-rock fractions) were ultrasonically cleaned, then one was leached in cold $0.5 \mathrm{M} \mathrm{HNO}_{3}$ and hot $6 \mathrm{M} \mathrm{HCL}$ with dissolution in the mixture of $\mathrm{HF}$ and $\mathrm{HNO}_{3}$, while the second fraction was dissolved without acid leaching. $\mathrm{Sr}$ was separated using cation exchange chromatography with $\mathrm{Sr}$ Spec resin and measured by three-line multidynamic method on the Triton Plus at RSES, ANU.

For our set of achondrites, we have got following initial ${ }^{87} \mathrm{Sr} /{ }^{86} \mathrm{Sr}$ ratios: $0.698961 \pm 0.000016$ for Ibitira, $0.698972 \pm 0.000008$ for Asuka 881394, 0.698934 \pm 0.000026 for NWA $11119,0.699004 \pm 0.000004$ for NWA 7325, $0.698982 \pm 0.000011$ for NWA $8661,0.698995 \pm 0.000025$ for NWA 6704, and $0.6990242 \pm 0.0000076$ for NWA 4587 . ALM-A has high measured ${ }^{87} \mathrm{Sr} /{ }^{86} \mathrm{Sr}$ of $0.703521 \pm 0.000007$ and therefore gives an imprecise initial value of $0.699050 \pm 0.000118$.

Our results show that, while the initial ${ }^{87} \mathrm{Sr} /{ }^{86} \mathrm{Sr}$ ratios of other achondrites are higher than the CAI value [4], and are apparently suitable for evaluation of the accretion timing, the initial ${ }^{87} \mathrm{Sr} /{ }^{86} \mathrm{Sr}$ ratios of Ibitira and Asuka 881394 are indistinguishable from the CAIs value, and NWA 11119 has the lowest initial ${ }^{87} \mathrm{Sr} /{ }^{86} \mathrm{Sr}$ measured in achondrites so far that is $\sim 0.6 \varepsilon$-units below the CAI value. These data and recent findings of CAIs with variable initial ${ }^{87} \mathrm{Sr} /{ }^{86} \mathrm{Sr}$ ratios [5] suggest heterogeneous distribution of ${ }^{87} \mathrm{Sr} /{ }^{86} \mathrm{Sr}$ in the solar nebula and complicate age detetmination with the initial ${ }^{87} \mathrm{Sr} /{ }^{86} \mathrm{Sr}$ chronometry.

[1] Papanastassiou, D. A. and G. J. Wasserburg (1969) EPSL, 5, 361-376. [2] Lodders, K. (2003) AJ, 2, 1220-1247. [3] Halliday, A. N. and D. Porcelli (2001) EPSL, 4, 545-559. [4] Hans, U., et al. (2013) EPSL, 374, 204-214. [5] Di, Y. and Y. Amelin (2020), LPSC, 1132. 